\title{
Adverse drug reactions from psychotropic medicines in the paediatric population: analysis of reports to the Danish Medicines Agency over a decade
}

\author{
Lise Aagaard*1,2 and Ebba H Hansen ${ }^{1,2}$
}

\begin{abstract}
Background: The prescribing of psychotropic medicines for the paediatric population is rapidly increasing. In attempts to curb the use of psychotropic medicine in the paediatric population, regulatory authorities have issued various warnings about risks associated with use of these products in childhood. Little evidence has been reported about the adverse drug reactions (ADRs) of these medicines in practice. As spontaneous reports are the main source for information about previously unknown ADRs, we analysed data submitted to a national ADR database. The objective was to characterise ADRs reported for psychotropic medicines in the Danish paediatric population over a decade.

Findings: All spontaneous ADR reports from 1998 to 2007 for children from birth to 17 years of age were included. The unit of analysis was one ADR. We analysed the distribution of ADRs per year, seriousness, age and gender of the child, suspected medicine and type of reported ADR. A total of 429 ADRs were reported for psychotropic medicines and 56\% of these were classified as serious. Almost $20 \%$ of psychotropic ADRs were reported for children from birth up to 2 years of age and one half of ADRs were reported in adolescents, especially for antidepressants and psychostimulants. Approximately $60 \%$ of ADRs were reported for boys. Forty percent of all ADRs were from the category 'nervous and psychiatric disorders'. All but one ADR reported for children below two years were serious and two of these were fatal. A number of serious ADRs reported in children from birth up to 2 years of age were presumably caused by mothers' use of psychotropic medicines during pregnancy.
\end{abstract}

Conclusion: The high number of serious ADRs reported for psychotropic medicines in the paediatric population should be a concern for health care professionals and physicians. Considering the higher number of birth defects being reported greater care has to be given while prescribing these drugs for pregnant women.

\section{Background}

The prescribing of psychotropic medicines for the paediatric population is rapidly increasing in many countries including Denmark. In attempts to curb the use of psychotropic medicine in the paediatric population, regulatory authorities have issued various warnings about risks associated with use of these products in childhood [1-4]. A systematic review detected seventeen studies since 2000 that reported information about the occurrence of

\footnotetext{
*Correspondence: laa@farma.ku.dk

1 Department of Pharmacology and Pharmacotherapy, Section for Social Pharmacy, Faculty of Pharmaceutical Sciences, University of Copenhagen, Denmark

Full list of author information is available at the end of the article
}

ADRs in paediatric populations [5]. Nearly one third of all ADRs reported in children were due to psychotropic medicines, especially CNS stimulants and antidepressants. However, more detailed information about the characteristics of ADRs from psychotropic medicines in the general paediatric population is lacking and little evidence has been reported about safety and long-term effects of these medicines in practice [6-8]. Lack of knowledge of adverse drug reactions (ADRs) at the point of licensing of new medicines renders spontaneous ADR reporting an important contributor to knowledge about safety of medicines [9]. As spontaneous reports are the main source for information about new and previous 
unknown ADRs we conducted an analysis of all spontaneous ADR reports for psychotropic medicines in Denmark from 1998 to 2007.

\section{Methods}

We used data from the national Danish ADR database, which contains information about all spontaneous reports submitted to the Danish Medicines Agency (DKMA) [10]. ADRs reported for children from 0 to 17 years of age were included. We analysed the distribution of ADRs per year, seriousness, age and gender of the child, suspected medicine and type of reported ADR (system organ class [SOC]). ADRs were classified as serious on the following criteria: death, life-threatening, requiring hospitalisation or prolongation of existing hospitalisation, resulting in persistent or significant disability/ incapacity, a congenital anomaly/birth defect and other medically important conditions.

\section{Results}

\section{ADRs over time}

From 1998 to 2007 a total of 2437 individual ADR reports containing information about 4500 ADRs were reported for children. Of these, 210 reports corresponding to 429 ADRs were submitted for psychotropic medicines. Figure 1 shows the annual distribution of the reported ADRs. There were wide fluctuations in the number of ADRs reported annually, with an increase in number from 2003 to 2005 followed by a decrease in 2006 and 2007 .

\section{ADRs by age and seriousness}

Table 1 shows the distribution of reported ADRs by therapeutic group and medicine, age of patient and seriousness. Almost one fifth of ADRs were reported for children below 2 years and one half of all ADRs were reported for adolescents (from 11 to 17 years of age), and $45 \%$ of these were serious. Totally, $59 \%$ of all ADRs were reported for boys. More than one half of all ADRs were classified as 'serious'. Table 2 displays characteristics of ADRs reported for children below two years. Two deaths were reported for citalopram and fluoxetin due to chorioamnionitis and persistent foetal circulation, respectively. ADRs among children up to 2 years of age encompassed a wide range of reactions, e.g. convulsion, feeding disorder, neonatal priapism, apnoea and ventricular septal defects. Seven ADRs: drug exposure during pregnancy, neonatal respiratory depression, apnoea and pallor were reported as "maternal drugs affecting foetus". However, the remaining ADRs were probably also caused by mothers' use of psychotropic medicines during pregnancy, as the indications for use were reported as depression, anxiety, panic disorder and schizophrenia. The share of serious psychotropic ADRs was higher than the share of serious ADRs in Danish children in general (40\%) [11]. In the general Danish paediatric population, half of all ADRs were reported in children from birth up to 2 years of age, but for psychotropic medicines more than half of all ADRs were reported for adolescents which reflect a more extensive use of psychotropic medicine in 11 to 17 - year-

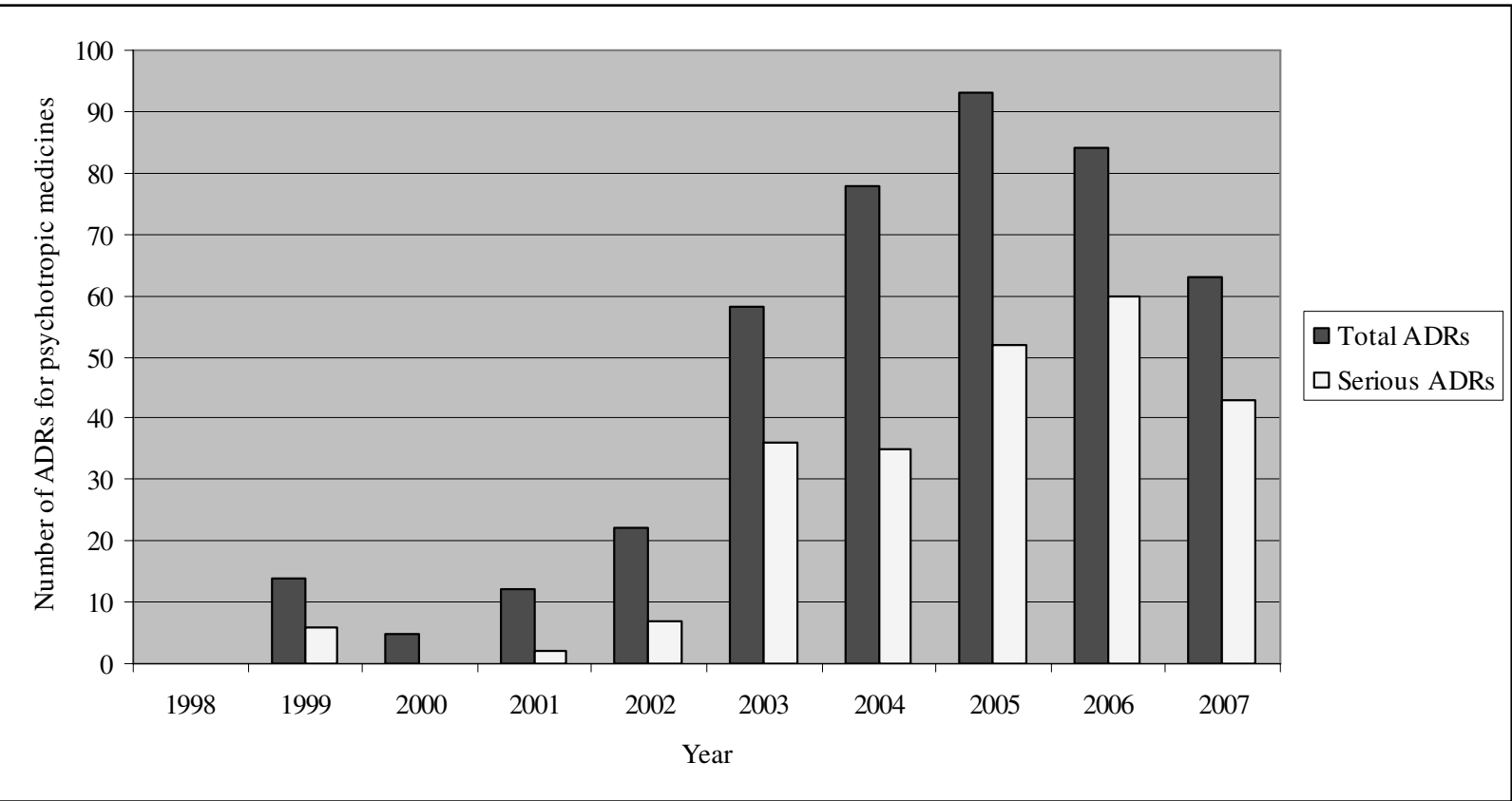

Figure 1 Annual number of adverse drug reactions (ADRs) for psychotropic medicines reported in the Danish paediatric population 
Table 1: Number of adverse drug reactions reported for psychotropic medication in the paediatric population by age and seriousness (in italic) (1998 to 2007)

\begin{tabular}{|c|c|c|c|c|c|}
\hline Age groups (years) & $<1$ & $1<2$ & $2-10$ & $11<17$ & Total \\
\hline \multicolumn{6}{|c|}{ Antipsychotics (N05A) } \\
\hline Levomepromazine & $1(1)$ & 0 & 0 & 1 & $2(1)$ \\
\hline Zipradison & 0 & 0 & 2 & $16(11)$ & $18(11)$ \\
\hline Zuclopenthixol & $1(1)$ & 0 & 0 & $1(1)$ & $2(2)$ \\
\hline Chlorprothixene & 0 & 0 & 0 & 2 & 2 \\
\hline Clozapine & 0 & 0 & 0 & 1 & 1 \\
\hline Olanzapine & $8(8)$ & $5(5)$ & 0 & $11(3)$ & $24(16)$ \\
\hline Quetiapine & $1(1)$ & 0 & $1(1)$ & $14(12)$ & $16(14)$ \\
\hline Sulpiride & 0 & 0 & 0 & 3 & 3 \\
\hline Risperidone & $1(1)$ & 0 & 5 & $18(5)$ & $24(6)$ \\
\hline Aripiprazol & 0 & 0 & 0 & $14(3)$ & $14(3)$ \\
\hline Total & $12(12)$ & $5(5)$ & $8(1)$ & $81(35)$ & $106(53)$ \\
\hline \multicolumn{6}{|c|}{$\begin{array}{l}\text { Hypnotics and sedatives } \\
\text { (N05B/N05C) }\end{array}$} \\
\hline Diazepam & $1(1)$ & 0 & 0 & 0 & $1(1)$ \\
\hline Oxazepam & $3(3)$ & 0 & 0 & 0 & $3(3)$ \\
\hline Buspirone & $1(1)$ & 0 & 0 & 0 & $1(1)$ \\
\hline Chloral hydrate & 0 & 0 & $3(3)$ & 0 & $3(3)$ \\
\hline Midazolam & 0 & 0 & $1(1)$ & $2(2)$ & $3(3)$ \\
\hline Total & $5(5)$ & 0 & $4(4)$ & $2(2)$ & $11(11)$ \\
\hline \multicolumn{6}{|c|}{ Antidepressants (N06A) } \\
\hline Imipramine & 0 & 0 & $1(1)$ & 0 & $1(1)$ \\
\hline Clomipramine & $1(1)$ & 0 & 0 & 0 & $1(1)$ \\
\hline Amitriptyline & $2(2)$ & 0 & 0 & 0 & $2(2)$ \\
\hline Fluoxetine & $14(14)$ & 0 & 0 & $1(1)$ & $15(15)$ \\
\hline Citalopram & $17(17)$ & $4(4)$ & $5(2)$ & $10(6)$ & $36(29)$ \\
\hline Paroxetine & $5(4)$ & 0 & 0 & $6(2)$ & $11(6)$ \\
\hline Sertralin & $11(11)$ & 0 & $9(3)$ & $25(20)$ & $45(34)$ \\
\hline Escitalopram & $1(1)$ & $1(1)$ & 0 & 0 & $2(2)$ \\
\hline Oxitriptan & 0 & 0 & 0 & 3 & 3 \\
\hline Mirtazapin & $1(1)$ & 0 & 0 & $12(8)$ & $13(9)$ \\
\hline Venlafaxin & $1(1)$ & 0 & 0 & 3 & $4(1)$ \\
\hline Total & $53(52)$ & $5(5)$ & $15(6)$ & $60(37)$ & $133(100)$ \\
\hline \multicolumn{6}{|c|}{ Psychostimulants (N06B) } \\
\hline Methylphenidate & 0 & 0 & $85(35)$ & $44(17)$ & $129(52)$ \\
\hline Modafinil & 0 & 0 & 0 & $7(7)$ & $7(7)$ \\
\hline Atomoxetine & 0 & 0 & $23(7)$ & $20(11)$ & $43(18)$ \\
\hline Total & 0 & 0 & $108(42)$ & $71(35)$ & $179(77)$ \\
\hline Total N05 and N06 & $70(69)$ & $10(10)$ & $135(53)$ & 214 (109) & $429(241)$ \\
\hline
\end{tabular}


Table 2: Serious ADRs from psychotropic medicines reported for children below two years of age (1998 to 2007)

\begin{tabular}{|c|c|c|c|c|c|}
\hline ATC & Medicines & Adverse drug reaction & No & Indication of use & Age ofchild \\
\hline \multirow[t]{17}{*}{ N05A } & Levopromazine & Priapism & 1 & Headache & 0 \\
\hline & Olanzapine & Atrial septal defects & 1 & NA & 1 \\
\hline & & Blood glucose decreased & 1 & Schizophrenia & 0 \\
\hline & & Convulsion & 1 & NA & 0 \\
\hline & & Decreased appetite & 1 & Schizophrenia & 0 \\
\hline & & Drug exposure during pregnancy & 1 & $N A^{*}$ & 0 \\
\hline & & Failure to thrive & 1 & Schizophrenia & 0 \\
\hline & & Feeding disorder, neonatal & 1 & Schizophrenia & 0 \\
\hline & & Haemoglobin increased & 1 & NA & 1 \\
\hline & & Hypoxia & 1 & NA & 0 \\
\hline & & Pneumonia & 1 & NA & 1 \\
\hline & & Polycythaemia & 1 & NA & 1 \\
\hline & & Somnolence & 1 & Schizophrenia & 0 \\
\hline & & Tension & 1 & NA & 1 \\
\hline & Risperidon & Drug withdrawal syndrome, neonatal & 1 & Depression & 0 \\
\hline & Sulpirid & Agitation, neonatal & 1 & Depression & 0 \\
\hline & Zuclopemthixol & Supraventricular tachycardia & 1 & Schizophrenia & 0 \\
\hline \multirow[t]{5}{*}{ N05B } & Buspirone & Ventricular septal defect & 1 & Depression & 0 \\
\hline & Diazepam & Apnoea & 1 & Convulsions & 0 \\
\hline & Oxazepam & Congenital acrochordon & 1 & Anxiety depression & 0 \\
\hline & & Chondropathy & 1 & Anxiety depression & 0 \\
\hline & & Drug exposure during pregnancy & 1 & Anxiety depression & 0 \\
\hline \multirow[t]{21}{*}{ N06A } & Amitriptyline & Epilepsy & 1 & Depression & 0 \\
\hline & & Febrile convulsion & 1 & Depression & 0 \\
\hline & Clompipramine & Psychomotor retardation & 1 & NA & 0 \\
\hline & Citalopram & Tremor, neonatal & 3 & Panic disorder & 1 \\
\hline & & Drug withdrawal syndrome, neonatal & 2 & Depression/Panic disorder & $0 / 1$ \\
\hline & & Hypotonia, neonatal & 2 & Depression & 0 \\
\hline & & Irritability & 2 & Panic disorder & $0 / 1$ \\
\hline & & Apnoea & 1 & $N A^{*}$ & 0 \\
\hline & & Asthenia & 1 & NA & 0 \\
\hline & & Chorioamnionitis & 1 & Depression & 0 \\
\hline & & Convulsion, neonatal & 1 & Depression & 0 \\
\hline & & Hypertonia & 1 & Panic disorder & 1 \\
\hline & & Hypocalcaemia & 1 & Depression & 0 \\
\hline & & Neonatal asphyxia & 1 & Depression & 0 \\
\hline & & Neonatal respiratory depression & 1 & $N A^{*}$ & 0 \\
\hline & & Oral candidiasis & 1 & Depression & 0 \\
\hline & & Pallor & 1 & $N A^{*}$ & 0 \\
\hline & & Premature labour & 1 & Depression & 0 \\
\hline & & Ventricular septal defect & 1 & Depression & 0 \\
\hline & Escitalopram & Atrial septal defect & 1 & NA & 1 \\
\hline & & Drug exposure during pregnancy & 1 & $N A^{*}$ & 0 \\
\hline
\end{tabular}


Table 2: Serious ADRs from psychotropic medicines reported for children below two years of age (1998 to 2007)

\begin{tabular}{|c|c|c|c|c|}
\hline \multirow[t]{12}{*}{ Fluoxetine } & Drug withdrawal syndrome, neonatal & 3 & Depression & 0 \\
\hline & Tremor & 2 & Depression & 0 \\
\hline & Agitation, neonatal & 1 & Depression & 0 \\
\hline & Bradycardia, neonatal & 1 & Depression & 0 \\
\hline & Deafness neurosensory & 1 & NA & 0 \\
\hline & Drug exposure during pregnancy & 1 & $N A^{*}$ & 0 \\
\hline & Dyskinesia, neonatal & 1 & Depression & 0 \\
\hline & Feeding disorder, neonatal & 1 & Depression & 0 \\
\hline & Hypertonia, neonatal & 1 & Depression & 0 \\
\hline & Neonatal disorder & 1 & Depression & 0 \\
\hline & Persistent foetal circulation & 1 & Depression & 0 \\
\hline & Upper limb deformity & 1 & Depression & 0 \\
\hline \multirow[t]{3}{*}{ Paroxetine } & Klinefelter's syndrome & 1 & NA & 0 \\
\hline & Neonatal respiratory failure & 1 & $N A^{*}$ & 0 \\
\hline & Psychomotor retardation & 1 & NA & 0 \\
\hline \multirow[t]{10}{*}{ Sertraline } & Respiration abnormal & 2 & Depression & 0 \\
\hline & Cerebral palsy & 1 & Depression & 0 \\
\hline & Circulatory collapse & 1 & Depression & 0 \\
\hline & Cyanosis & 1 & Depression & 0 \\
\hline & Drug withdrawal syndrome, neonatal & 1 & Depression & 0 \\
\hline & Drug exposure during pregnancy & 1 & Depression & 0 \\
\hline & Muscle spasms & 1 & Anxiety & 0 \\
\hline & Myoclonus & 1 & Anxiety & 0 \\
\hline & Persistent foetal circulation & 1 & Depression & 0 \\
\hline & Pulmonary hypertension & 1 & Depression & 0 \\
\hline Mirtazapine & Cerebral palsy & 1 & Depression & 0 \\
\hline Venlafaxine & Agitation, neonatal & 1 & Depression & 0 \\
\hline
\end{tabular}

*Indication for use not listed, but recorded as "Maternal drugs affecting foetus"; NA: not available

olds [9]. The majority of serious ADRs were reported in infants in contrast to reports submitted to Health Canada where $60 \%$ of all ADRs for psychotropic medicines were reported in 13 to 19 -year-olds, and only $12 \%$ in infants [12]. A number of ADRs were reported for Danish children below 2 years, probably due to the mother's intake of psychotropic medicine, primarily antidepressants and antipsychotics, during pregnancy. Serious ADRs such as 'neonatal withdrawal syndrome', 'ventricular septal defects' and 'premature labour' were reported. The risks of malformations as well as preterm delivery of babies due to use of antidepressants during pregnancy have been reported previously in the literature and is supported by our results [13-16].

\section{ADRs by therapeutic subgroups}

The largest share of ADRs (42\%) was reported for psychostimulants (ATC group N06B), followed by $31 \%$ for antidepressants (ATC group N06A) and 24\% for antipsychotics (ATC group N05A). More than one half of the ADRs reported for antipsychotics were caused by the drugs ziprasidone, olanzapine and risperidone. Although only $2.5 \%$ of ADRs were reported for anxiolytics and sedatives (ATC group N05B and N05C), predominantly in infants, all these ADRs were serious. Two-thirds of the ADRs reported for antidepressants (ATC group N06A) were reported for infants and adolescents and exclusively for the medicines sertraline, citalopram and fluoxetine and seventy-five percent of these were serious. For psychostimulants (ATC group N06B) 50\% of ADRs were serious and reported for children from six to nine years of age, and $40 \%$ of the reports were associated with methylphenidate and atomoxetine. With one exception, all 70 ADRs reported for children less than one year of age were serious. 
Table 3: Adverse drug reactions from psychotropic medicines by system organ class (descending order)

\begin{tabular}{|c|c|c|c|}
\hline \multirow[t]{2}{*}{ System Organ Class (SOC) } & \multirow{2}{*}{$\begin{array}{r}\text { All ADRs (\%) } \\
\text { N }=429\end{array}$} & \multirow{2}{*}{$\begin{array}{r}\text { Serious as \% of all ADRs } \\
N=241\end{array}$} & \multirow[t]{2}{*}{ Serious as $\%$ of ADRs } \\
\hline & & & \\
\hline Psychiatric disorders & 20 & 25 & 70 \\
\hline Nervous system disorders & 19 & 26 & 77 \\
\hline General disorders and administration site conditions & 12 & 7 & 33 \\
\hline Skin and subcutaneous tissue disorders & 8 & 3 & 21 \\
\hline Gastrointestinal disorders & 8 & 6 & 41 \\
\hline Cardiac disorders & 5 & 6 & 67 \\
\hline Investigations & 5 & 6 & 67 \\
\hline Respiratory, thoracic and mediastinal breast disorders & 4 & 4 & 59 \\
\hline Metabolism and nutrition disorders & 3 & 2 & 38 \\
\hline Musculoskeletal and connective tissue disorders & 3 & 4 & 77 \\
\hline Congenital, familial and genetic disorders & 2 & 4 & 77 \\
\hline Reproductive system and breast disorders & 2 & 1 & 22 \\
\hline Vascular disorders & 2 & 2 & 56 \\
\hline Others & 7 & 4 & 33 \\
\hline
\end{tabular}

\section{ADRs by type}

Table 3 shows the distribution of reported ADRs by system organ class (SOC). The largest shares of ADRs were reported for the SOCs 'psychiatric disorders' (20\% of total), 'nervous system disorders' (20\% of total) and 'general disorders and administration site conditions' (12\% of total). Less than $1 \%$ of the total number of reports concerned the following SOCs: 'ear and labyrinth disorders', 'endocrine disorders', 'hepatobiliary disorders', 'immune system disorders', 'pregnancy, puerperium and perinatal conditions' and 'surgical and medical procedures'. The largest shares of serious ADRs, about $25 \%$ of all were reported for the SOCs: 'psychiatric disorders' and 'nervous system disorders'. The distribution between serious and non-serious ADRs within SOCs varied. More than seventy-five percent of ADRs reported from the SOCs: 'nervous system disorders', 'musculoskeletal and connective tissue disorders' and 'congenital, familial and genetic disorders'were serious.

\section{Implications}

There are huge gaps in the evidence on the safety of medicines in children as only few medicines prescribed for children are tested in clinical trials and licensed for use in this population. In addition, information about serious and long-term ADRs is sparse due to the limitations embedded in the design of randomised, controlled clinical trials which are used primarily to test hypotheses about efficacy rather than safety and children are usually excluded from clinical trials of medicines for ethical reasons [17]. Therefore, it is very important to systematically analyse and evaluate data reported to the spontaneous reporting programmes as these reports are the major source for new information about possibly serious and previously unknown ADRs [18]. Several of the reported ADRs were birth defects, an area where we have very limited knowledge.

\section{Conclusions}

The high number of serious ADRs reported for psychotropic medicines in the paediatric population should be a concern for health care professionals and physicians. Considering the higher number of birth defects being reported greater care has to be given while prescribing these drugs for pregnant women.

\section{Competing interests}

The authors declare that they have no competing interests.

\section{Authors' contributions}

$\mathrm{LA}$ and $\mathrm{EHH}$ designed the study, analysed data and wrote the first version of the manuscript. LA did the sampling. Both authors read and approved the final version of the manuscript.

\section{Acknowledgements}

We would like to thank the Danish Medicines Agency for placing data at our disposal.

\section{Author Details}

'Department of Pharmacology and Pharmacotherapy, Section for Social Pharmacy, Faculty of Pharmaceutical Sciences, University of Copenhagen, Denmark and ${ }^{2} \mathrm{FKL}$ Research Centre for Quality in Medicine Use,

Universitetsparken 2, DK- 2100 Copenhagen, Denmark

Received: 18 March 2010 Accepted: 23 June 2010

Published: 23 June 2010 


\section{References}

1. European Medicines Agency/CHMP/128918/2005: Press Release: European Medicines Agency finalises review of antidepressants in children and adolescents. [http://www.ema.europa.eu/pdfs/human/ press/pr/12891805en.pdf]. [Accessed 18 February 2010]

2. Meeting highlights from the Committee for Medicinal Products for Human Use (EMEA/431407/2007) [http://www.emea.europa.eu/pdfs/ human/press/pr/43140707en.pdf]. [Accessed 18 February 2010]

3. European Medicines Agency makes recommendations for safer use of Ritalin and other methylphenidate-containing medicines in the EU (EMEA/22315/2009) [http://www.ema.europa.eu/pdfs/human/referral/ methylphenidate/2231509en.pdf]. [Accessed 18 February 2010]

4. Cheung A, Sacks D, Dewa CS, Pong J, Levitt A: Paediatric prescribing practices and the FDA Black-box warning on antidepressants. J Dev Behav Pediatr 2008, 29:213-15.

5. Aagaard L, Christensen AC, Hansen EH: Information about adverse drug reactions reported in children: a qualitative review of empirical studies. Br J Clin Pharmacol 2010 in press.

6. Garland EJ: Facing the evidence: antidepressant treatment in children and adolescents. CMAJ 2004, 170:489-91.

7. Riddle MA, Labellarte MJ, Walkup JT: Paediatric psychopharmacology: problems and prospects. J Child Adolesc Psychopharmacol 1998, 8:87-97.

8. Neubert A, Dormann H, Weiss J, Egger T, Criegee-Rieck M, Rascher W, Brune K, Hinz B: The impact of unlicensed and off-label drug use on adverse drug reactions in paediatric patients. Drug Saf 2004, 27:1059-67.

9. Aagaard L, Thirstrup S, Hansen EH: Opening the white boxes: The licensing documentation of efficacy and safety of psychotropic medicines for children. Pharmacoepidemiol Drug Saf 2009, 18:401-11.

10. Aagaard L, Stenver DI, Hansen EH: Structures and processes in spontaneous reporting systems: a comparative study of Australia and Denmark. Pharm World Sci 2008, 30:563-70.

11. Aagaard L, Weber $C B$, Hansen $E H$ : Adverse drug reactions in the paediatric population in Denmark: a retrospective analysis of reports made to the Danish Medicines Agency from 1998 to 2007. Drug Saf 2010, 33:327-29

12. Carleton BC, Smith MA, Gelin MN, Heathcote SC: Paediatric adverse drug reaction reporting: understanding and future directions. Can J Clin Pharmacol 2007, 14:e45-e57.

13. Dobson R: SSRI use during pregnancy is associated with fetal abnormalities. BMJ 2006, 333:824.

14. Wogelius P, Nørgaard M, Gislum M, Pedersen L, Munk E, Mortensen PB, Lipworth L, Sørensen HT: Maternal Use of Selective Serotonin Reuptake Inhibitors and Risk of Congenital Malformations. Epidemiology 2006, 17:701-4

15. Cuevas DC, Sanz EJ: Safety of selective serotonin reuptake inhibitors in pregnancy. Curr Drug Saf 2006, 1:17-24.

16. Lund N, Pedersen LH, Henriksen TB: Selective serotonin reuptake inhibitor exposure in utero and pregnancy outcomes. Arch Pediatr Adolesc Med 2009, 163:949-54

17. Hansen EH: Technology assessment in a user perspective- experiences with drug technology. Int J Techn Assess Health Care 1992, 8:150-65

18. Aagaard L, Hansen EH: Information about adverse drug reactions explored by pharmacovigilance approaches: a qualitative review of studies on antibiotics, SSRIs and NSAIDs. BMC Pharmacology 2009, 9:4.

doi: 10.1186/1756-0500-3-176

Cite this article as: Aagaard and Hansen, Adverse drug reactions from psychotropic medicines in the paediatric population: analysis of reports to the Danish Medicines Agency over a decade BMC Research Notes 2010, 3:176

\section{Submit your next manuscript to BioMed Central} and take full advantage of:

- Convenient online submission

- Thorough peer review

- No space constraints or color figure charges

- Immediate publication on acceptance

- Inclusion in PubMed, CAS, Scopus and Google Scholar

- Research which is freely available for redistribution

Submit your manuscript at www.biomedcentral.com/submit
C Biomed Central 